\title{
Practice of Graduate Students Assisting Teachers to Teach Pharmacy Major Courses in Local Normal University
}

\author{
Pengwu Zheng, Zhen Xiao, Linxiao Wang, Shan Xu, Wufu Zhu* \\ School of Pharmacy, Jiangxi Science\& Technology Normal University, Nanchang, China \\ Zhuwufu-1122@163.com
}

\begin{abstract}
Graduate student assisting teaching is an important position for graduated student who major in Analytical Chemistry and Pharmaceutical Chemistry. In order to improve their ability of majors, and enhance their professional competitiveness, reformation methods of the graduated student assistant teaching was carried out in this paper. Two kinds of method including traditional way and new method were applied in different graduated student of Analytical Chemistry and Pharmaceutical Chemistry. After one year practice the graduated student from two major of Analytical Chemistry and Pharmaceutical Chemistry exhibit different satisfied toward the traditional way and new method, respectively. The results showed that the new method much better and the graduated student show higher enthusiasm and finished the assisting work better and fast.
\end{abstract}

Keywords-Graduate student assisting teaching; School of pharmacy; Reformation

\section{INTRODUCTION}

Graduate Students' Three Assisting Acts contain three aspects: assistant teaching, assistant researching and assistant management, respectively. Among them, the duty of the graduated student assist teaching is to assistant the teacher to management the undergraduate student and help them finish the daily tasks. What's more, the assisting management is also a choice for the graduate student to enhance their professional competitiveness and decrease their economic pressure [1-2].
Graduate student assistant teaching is an important specialized position for the student majoring in pharmacy and pharmaceutical engineering. Through the position of assistant teaching, the pharmacy theories and the skill of practice of the graduate student could be better understand and improved. And it also can decrease the teaching pressure of the teacher. What's more, it is also a choice to enhance their professional competitiveness and decrease the economic pressure for the graduated student. Therefore, the position of assistant teaching play an important role for the student of pharmacy chemistry, analysis chemistry and other similar majors [3].

Many of university of school of pharmacy in china set the position of assistant teaching for the graduate student majoring in analysis chemistry and pharmaceutical chemistry. In most of the university, the position of graduated student assistant teaching was operated by a traditional way, that is "teacher teach graduated student + graduated student teach undergraduate student" mode, even some "985"and " 211 " pharmaceutical universities, such as China Pharmaceutical University and Shenyang Pharmaceutical University (Table.1). There are few evaluation among the teacher, graduate student and undergraduate student, and don't have a useful system to operation and regulate the position of graduated student assistant teaching. Moreover, the low reward and lack of coordination were also the rational explanation for the poor efficiency assistant teaching. But, little reformation of the position of graduated student assistant teaching was carried out in these universities. Therefore, the reformation of position of graduated student assistant teaching is necessary. 


\section{\begin{tabular}{c}
\hline Item \\
\hline $\begin{array}{c}\text { Discussion among the graduate and } \\
\text { teacher }\end{array}$
\end{tabular}}

\section{Assistant teaching reward}

Assistant teaching method

\section{The mode of assistant teaching reformation}

Most university in china

Jiangxi science technology normal university

Few Often

Less

More

Teacher teaching graduate student

+ graduate teaching undergraduate student

New methods
As we know, analysis chemistry major and pharmacy chemistry majors are applied majors and the graduate student of these two majors need more practice. Only learning professional knowledge constantly that the graduate student can understand and master these professional skills well. Moreover, when they work in company, they are competent for their position.

What's more, the position of graduated student assistant teaching was an important moiety to decrease the economic pressure of graduate student and the reward is need to improve a higher level. While the traditional reward regulation can't relieve the economic pressure of the graduate student.

Therefore, the reformation of graduated student assistant teaching of analysis chemistry and medicinal chemistry major is agent. Some reformation should be carried out for the position of graduated student assistant teaching, especially in local university.

Here, in this paper, we introduced one new method about the position of assistant teaching for graduate students in school of pharmacy, Jiangxi science technology normal university. And the merit and the demerit for the two methods were discussed.

\section{METHODS}

Method of comparative analysis, market research and analysis were applied in our project. [4-10]

Before we start this study, firstly, an investigation was carried out to study the position of graduated student assistant teaching of school of pharmacy of most of university in china. And then the results are the important basis for the assisting management position of school of pharmacy.

Secondly, according to the results, we design a reasonable plan for the reformation that is enhance the check regulation, improve the reward and add the evaluation of the graduated student. We carried out our plan in class and several pharmaceutical companies in Nanchang of Jiangxi provinces,
Few

Often which are near to our school so that we can decrease the spending of this project.

Thirdly, the material for the control and experiment group such as medium check table and satisfied evaluated table and so on.

We choose sixteen graduated student from analysis chemistry and medicinal chemistry major in school of pharmacy, Jiangxi science technology normal university as subject, respectively. And eight of them (named group one) was choose as the reference group using traditional assisting management method. The other group (named group two) was choose as experiment group using the reformed method.

We choose the same school, the same number of graduate student, the same teacher and the same time for the two group. For different group, we select different way for this investigation. We used new method for group two and a traditional method for group one.

Firstly, we change the mode of assistant teaching. In traditional, we teaching the graduated student through the traditional method of "teacher teaching graduated student + graduated teaching undergraduate student" in group one. While the group two, we teaching the graduate student not only through the traditional way, but also check was carried out and the regulation were build up to evaluate the work of the graduate student.

Secondly, the total assistant teaching time for group one and group two is the same. Here's 51 hours of theory in group one and with 200 reward while in group was added to 400 .

Thirdly, group one and group two were different in weather the report need to write to the teacher or not. In group one, no report was needed to write. While in group two, several times for discussions and exercise for each group were needed.

Finally, mid- examination and finally finally-examination were carried out in group two, and the scores in one of the important aspects for finally scores.

What's more, all the reformation were listed in the Table 2. 
TABLE II.

DIFFERENCES BETWEEN GROUP ONE AND GROUP TWO IN THIS PROJECT

\begin{tabular}{|c|c|c|}
\hline Groups & Group one & Group two \\
\hline Major & Analysis chemistry & Pharmaceutical chemistry \\
\hline Graduate student numbers & 8 & 8 \\
\hline Methods & Traditional methods & New methods \\
\hline The mode of assistant teaching & $\begin{array}{c}\text { teacher management graduate student } \\
+ \text { graduate management } \\
\text { undergraduate student }\end{array}$ & $\begin{array}{l}\text { Not only the traditional way, but also } \\
\text { discussion between the graduate } \\
\text { student and teacher, and with a } \\
\text { satisfied reward }\end{array}$ \\
\hline Discussion & No discussion & Several discussion for group two \\
\hline Reward & 200 & 400 \\
\hline Mid-examination & No mid-examination & $\begin{array}{l}\text { Taking mid-examination, and the } \\
\text { score is one of the important aspect } \\
\text { for finally scores }\end{array}$ \\
\hline Finally examination & Check table & $\begin{array}{l}\text { Not only need check table, but also } \\
\text { need be evaluated by the teacher and } \\
\text { the undergraduate students }\end{array}$ \\
\hline
\end{tabular}

\section{RESULTS}

After one years later, the new method was applied in school of pharmacy, Jiangxi science Technology normal university. Some test were carried out to evaluated weather the new method have some advantages compared with the traditional way. The results shown that the new method is better and the graduated student in group two do much more better about the assistant teaching than group one. We can easily find that the mean scores are much higher for the methods. What more, the student are more satisfied with the new methods while most of the student don't want to attend the traditional group one of the analysis chemistry.

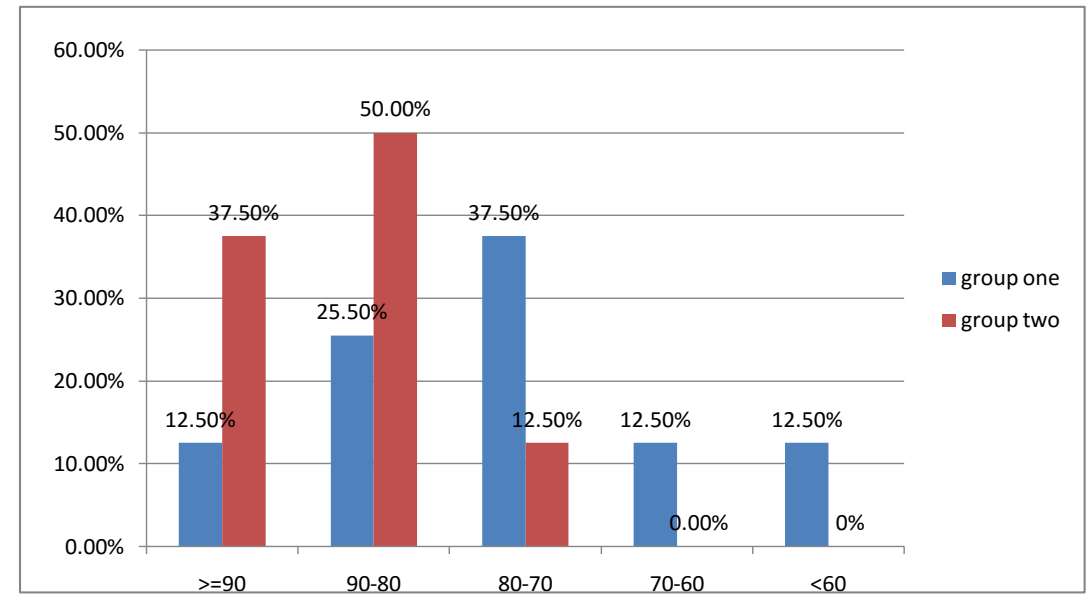

Fig. 1. Statistics of finally scores of the two group

From the Fig.1, we could see that the scores of the graduate student in group two are much better than that of graduate student in group one. What's more, $87.5 \%$ of the graduate student get the scores more than 80 and none of graduate student get less than 60 .
While in the group 1, the graduated student that the scores less than 60 is $12.5 \%$. This result told us that the graduate students in group two can do better than the group one, which using the new methods of assistant teaching compared with traditional methods. 


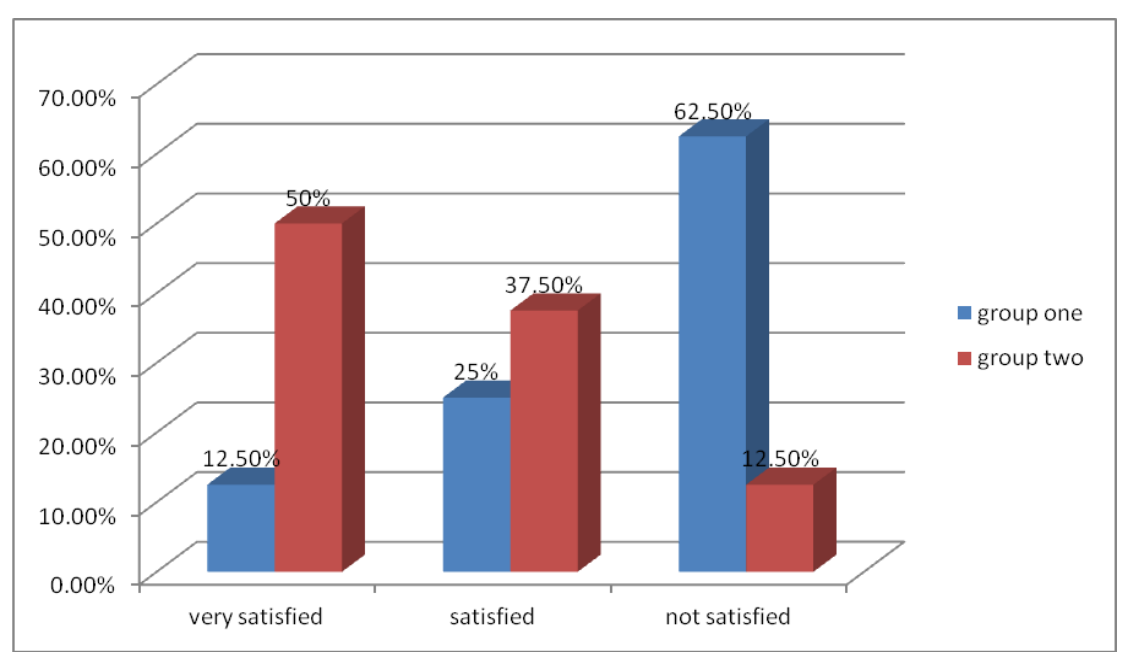

Fig. 2. Statistics of satisfaction degree of the two group toward the different assisting management methods

From Fig.2, we could know that the graduated student of group two were more satisfied with the assistant teaching methods, with $87.5 \%$ graduated students were satisfied and only one student $(12.5 \%)$ is not satisfied. While the numbers in group two were lower compared with the group one, and only $37.5 \%$ of the student satisfied with the traditional assistant teaching methods of analysis chemistry major. Importantly, these are nearly $62.5 \%$ of the students not satisfied with the traditional methods.

The efficiency of assistant teaching by the new methods was improved a lot and is much better than that of the traditional methods. It claimed that more reward and evaluate among the teacher, graduate student and undergraduate student play an important role in the success of the reformation of assistant teaching. The result also suggested that the new methods has many advantages.

\section{CONCLUSIONS}

In this paper, a discussion was carried out to investigate the graduated student assistant teaching between the traditional way and a new method. And. the different methods applied in the different major. The results showed that the new method has many advantages, such as decrease the economic pressure and improve the competent of the job.

This assistant teaching reformation could also be applied in other similarly other majors such as biopharmaceutical professional. And further study of this assistant teaching reformation will be carried out in the near future. We hope that the reformation of the assistant teaching will benefit to more and more graduated student, not only decrease their economic pressure but also improve their various ability.

\section{ACKNOWLEDGMENT}

We gratefully acknowledgment the generous support provided by the Academic Degrees \& Graduate Education teaching reform project of Jiangxi province (JXYJG-2017142\&JXYJG-2015-139).

\section{REFERENCES}

[1] Teaching assistant. (2017, April 10). In Wikipedia, The Free Encyclopedia. Retrieved 12:39, July 8, 2017,from https://en.wikipedia.org/w/index.php?title=Teaching_assistant\&oldid=7 74819306

[2] Student assistant. (2015, March 7). In Wikipedia, The Free Encyclopedia. Retrieved 12:41, July 8, 2017, from https://en.wikipedia.org/w/index.php?title=Student_assistant\&oldid=650 294278

[3] Xiaoshan K, Zhaojun G, Tingting Y. Analysis of the Roles, Problems and Strategies of "Three Assistance" [J]. Journal of Beijing University of Posts And Telecommunications: social science edition, 2010, 12(4):104-108.

[4] Xinhui P, Xinbing W, Dongmei Q, et al. A Brief Probe into How to Cultivate Students' Creative Ability on Medicinal Chemistry [J]. The Science Education Article Collects, 2015, 2: 028.

[5] Zhao Q, Shen Z, Liu W. The Reforming Research of Pharmaceutical Chemistry Experiment in Transformation of Local Colleges and Universities [J]. Guangzhou Chemical Industry, 2015, 6: 071.

[6] Wang Z, Huang Q. Application of PBL in Experimental Teaching of Medicinal Chemistry [J]. Guangzhou Chemical Industry, 2015, 1: 071.

[7] Islam M A, Schweiger T A. Students' Perception of an Integrated Approach of Teaching Entire Sequence of Medicinal Chemistry, Pharmacology, and Pharmacotherapeutics Courses in PharmD Curriculum[J]. Journal of pharmacy practice, 2015, 28(2): 220-226.

[8] Johnson B J, Graham K J. A Guided Inquiry Activity for Teaching Ligand Field Theory [J]. Journal of Chemical Education, 2015, 92(8):1369-1372.

[9] Cullen D M. Modeling Instruction: A Learning Progression That Makes High School Chemistry More Coherent to Students [J]. Journal of Chemical Education, 2015, 92(8): 1269-1272.

[10] Singh P. CBL in Medical Education Effective Learning Methodology than PBL [J]. International Journal of Integrative Medical Sciences, 2015, 2(8): 145-50. 